\title{
Do we support our governments to use strict surveillance methods in the fight against the coronavirus?
}

\author{
Keziah Akhigbemen, Ade (Sherifat) Bakare, Hollie Bingham, Eloise \\ Crossland, Matthew Cupac, Molly Jones, Darill Zeng Liew, Shaunna \\ McIvor, Katerina Nicosia, Pooja Raval, Chris Shipley, Iona Smith, \\ Brandon Swift, Will Tyson and Leonie Williams ${ }^{1}$
}

\begin{abstract}
Chinese-style surveillance is coming to a neighborhood near you. From drones barking orders at park-goers to tracing people's movements through mobile phones, the governments all over the world are now rushing to embrace sophisticated surveillance tools that would have been unthinkable just a few weeks ago. Unprecedented use of surveillance technology, such as the use of tracking bands by the Hong Kong government or phone tracking by the Taiwanese government to ensure self-quarantining patients do not leave their homes, are indeed accepted by the local population, since they believe the fight against the coronavirus is a collective effort and believe in sacrificing these freedoms momentarily for the collective good.
\end{abstract}

In many western countries the governments have taken the unprecedented step of asking telecoms companies to hand over mobile phone data so they can track population movements and try to stop the spread. As coronavirus surveillance escalates, personal privacy plummets. Understandably, much of the current commentary on the virus still focusses on the fluid situation regarding the number of infections, the mortality rate and the differing containment measures enacted by varying states.

Tracking entire populations to combat the pandemic could also open the doors to more invasive forms of government snooping later. Epidemiologists argue that such efforts are only a first step: To be fully effective, some say, we will have to follow the example of South Korea and China and make infected people download an app that would reveal exactly where they go and who they meet. It has been reported that credit card information too has been collected by governments in China and Singapore.

While governments seek out more effective tracking tools, companies best known for providing digital surveillance for security forces are proving only too happy to oblige. The race to embrace invasive tools underscores a simple dynamic at play during the current global pandemic: Public health concerns are trumping the desire to protect individuals' privacy online and in the real world, sweeping privacy rules.

With the last major global pandemic being the Spanish Flu in 1918, when globalization was hardly recognizable, there was little surveillance available to governments - and certainly not the technology that is available today. Yet, with increased globalization comes increased transmission, especially for viruses with high transmission rates like that of COVID-19. It is for this reason that states such as the US, the UK, China, South Korea, Russia and Cambodia have been reported to be using increased surveillance of their citizens. Government surveillance is not new, but its novel overtness, in combination with public 
support, is concerning as privacy remains an afterthought to the majority. Its goal on the surface is to protect our lives but, once the priority shifts from this, the immediate threat turns to protecting our privacy.

There is an understandable tendency to concentrate on the immediate and the visible, and nothing is more immediate and visible than the daily death toll. From this point of view, the coronavirus pandemic provides a rare opportunity for the state to strengthen its legitimacy as a securer of the life of its citizens. In normal times many people would be up in arms at this extreme level of citizen surveillance by the government, however, they don't seem to be bothered now and are ready to accept it enthusiastically within the panicked context of this once-in-a-generation health crisis. Many people think that surveillance is okay if we know exactly how long it is going to be used for, for example several weeks, even months, until the pandemic is under control. The governments should give a more realistic prediction of isolation time and introduce such measures accordingly, and not in an openended fashion. Especially if measures are becoming stricter, such as phone tracking.

We believe that it is vital to ensure that the liberty and privacy of populations is maintained and respected, even in times of international crisis. In relation to The Health Protection (Coronavirus) Regulations 2020, enacted by the UK government, the UK Human Rights Blog have commented that "an uphill struggle now looms to control the COVID-19 state". The measures implemented in various countries around the globe, particularly in South Korea, to tackle the coronavirus outbreak could be regarded as a threat to democracy and the principles of freedom and movement it encompasses. The implementation of the Coronavirus 2020 Bill in the UK has introduced a somewhat command society under the guise of "public health surveillance". The presentation of such "public health surveillance" as imperative to save lives and jobs raises several ethical questions that must be challenged in order to maintain freedom and the right to privacy.

Many of us would like to believe that the possible reward in allowing the government to implement further surveillance measures to tackle coronavirus is far outweighed by the risk. When everybody's health and wellbeing is paramount, and if surveillance seems to be the only way to control the virus, then of course it should be used for the greater good of society. In particular considering there are some people failing to comply with the governments' social distancing rules and regulations. There have been news reports on gatherings at house parties and at local parks, which show a complete lack of responsibility. The noncompliance of social distancing measures in Western countries often come from the more individualistic nature of the Western population - the thinking of "I am healthy enough to be infected, why should I care" is hampering efforts to contain the virus, and since an overnight change to this individualistic thinking is impossible it can be argued that only the use of surveillance methods can be effective in enforcing the social distancing measures that are crucial for the fight against coronavirus.

Since there are examples from other countries that technology does have a part to play in slowing the pandemic, it is normal the authorities everywhere are considering introducing such methods as tracking.

We hope to believe that the governments are likely to relinquish power when it is no longer needed. However, it is also possible that a system such as this would invite abuses and invasions of privacy. Using mobile phone data, in particular, is very invasive on personal privacy. By making people download an app if they are infected, isn't that essentially painting a target on their back? Article 8 of the Human Rights Act 1998 states that humans have the right to a private life. Just like the Patriot Act, it could possibly bestow upon the operator the ability to keep tighter tabs on an individual at their own discretion. Even if it is used carefully during the crisis, the next administration might not respect individual freedoms. Highly complex networked systems such as this are always vulnerable somewhere, and a government with a network such as this could possibly see it used in a way that conflicts 
Vol. 7, No. 1, 101-103.

with their interests, whether by a foreign power or by interest groups. The exact position and coronavirus status of all of your citizens would be far too powerful a weapon to fall into enemy hands - better to avoid the risk by not creating it.

There are certain types of surveillance that are more appropriate than others in this case, for example, potentially using location data from phones to monitor locations might be acceptable, but drones and other imaging surveillance are not necessary. It will be unrealistic to demand perfect safety simultaneous to perfect privacy. Taking the outbreak of coronavirus seriously means accepting that we may have to concede somewhat with regards to our individual privacy in order to secure the safety of the population at large. Are our states fully open and honest regarding what measures they are putting in place? It is imperative that, in order to enforce this most effectively, there should be an independent body designated to monitor this and hold the State accountable if they do not fully oblige. In pursuit of this, the governments must publicly justify each and every measure taken and engage in an ongoing process of review to determine the continuing efficacy and ethical implications of each measure. Secondly, it must be ensured that every measure is reversible, so that at the end of the pandemic we can return to our normal level of privacy. The panic built by the spread of the virus has meant that emergency legislation contains vague language and suggests intensive surveillance with either no reference to how long this will last or be enacted for. Such legislation exacerbates existing inequalities or disadvantages within society for those who are invisible to the state or with marginalized identities. This includes, but is not limited to, migrants with precarious immigration status, working class BAME communities, women and people within the LGBTQ+ community. A bigger issue is that enacting stricter surveillance methods during a time of panic and emergency means the public will be more accepting of it, increasing the social acceptance and normalization of such measures.

Where are the methods and measure put in place to protect the public's privacy? Even after surveillance is no longer needed, how do you know they will stop tracking you? People will find loopholes in these tracking devices and it would probably cause uproar as people do not like being controlled. Surveillance, however, is nothing new in the 21st century. Only this time the surveillance is more overt and is continuing with not only public knowledge but public support. Predicting what will happen after the pandemic is difficult, not least because we have little information about how long the outbreak and restrictions will last. But how do we know they aren't tracking us already?

\section{Note}

${ }^{1}$ Students in the final year Missing Dimension: Intelligence and International Relations module at Keele University. 